\title{
Interpretation of sedimentary (sub)populations extracted from grain size distributions of Central European loess-paleosol series
}

\author{
György Varga ${ }^{\mathrm{a}, \text { * }}$, Gábor Újvári ${ }^{\mathrm{b}}$, János Kovács ${ }^{\mathrm{c}, \mathrm{d}}$ \\ a Geographical Institute, Research Centre for Astronomy and Earth Sciences, Hungarian Academy of Sciences, H-1112, Budapest, Budaörsi út 45., Hungary \\ ${ }^{\mathrm{b}}$ Institute for Geological and Geochemical Research, Research Centre for Astronomy and Earth Sciences, Hungarian Academy of Sciences, H-1112, Budapest, Budaörsi u. 45., \\ Hungary \\ c Department of Geology and Meteorology, University of Pécs, H-7624, Pécs, Ifjúság u. 6., Hungary \\ d Environmental Analytical and Geoanalytical Laboratory, Szentágothai Research Centre, University of Pécs, H-7624, Pécs, Ifjúság u. 20., Hungary
}

\section{A R T I C L E I N F O}

\section{Article history:}

Received 31 May 2017

Received in revised form 14 August 2017

Accepted 21 September 2017

Available online $\mathrm{xxx}$

\section{Keywords:}

Loess

Grain size

Parametric curve-fitting

End-member modelling

Hierarchical cluster analysis

\begin{abstract}
A B S T R A C T
Grain size proxies of aeolian dust deposits have widely been applied in environmental and sedimentary studies. However, large body of research papers are not taking into consideration that a complex grain size distribution curve cannot be an indicator of a single one environmental factor (e.g. wind speed/strength, transportation distance, aridity).

The aim of the present paper is to discuss the main differences of frequently used statistical methods and to provide possible interpretations of the results by applying these various approaches on the high-resolution loess-paleosol profile of Dunaszekcsö, South Hungary (Central Europe). Beside single statistical descriptors (mean, median, mode) of grain size and simple indices of size-fraction ratios (U-ratio, Grain Size Index), some more complex algorithms were also used in our paper. The applied parametric curve-fitting, end-member modelling and hierarchical cluster analysis techniques are using the whole spectrum of the measured grain size distributions and provide a more reliable and more representative results even in case of small scale variations.

According to our findings, approaches which provide direct linkage among simple statistical descriptors and single atmospheric or other environmental elements are rather oversimplified as properties aeolian dust deposits are influenced by the integrated effects of several concurrent processes. Differences of more complex decomposition methods arise from the different approach and scope. End-members are determined from the unmixing based on the covariance structure of the whole grain size data-series of the section, while the parametric curve-fitting is based on the one-by-one deconvolution of the grain size distribution curves. End-members of loess-paleosol samples are regarded as representation of the average dust grain size distribution of various temporal sediment clusters of seasonal or other short-term intervals, while (sub)populations by parametric curve-fitting are proposed to illustrate process-related elements of background and dust storm depositional components for each sample. Results of cluster analysis represent similar grouping conditions as end-member modelling with a reduced sedimentary and genetically meaning.
\end{abstract}

(C) 2017

\section{Introduction}

Terrestrial aeolian dust deposits as loess-paleosol series are regarded as excellent archives of climatic and other environmental changes of the last $\sim 1$ million years in Central Europe (Smalley and Leach, 1978; Pécsi, 1990; Pye, 1995; Marković et al., 2011, 2015; Basarin et al., 2014; Buggle et al., 2014; Újvári et al., 2014). Particle size data of sedimentary deposits provide insights into the physicochemical environment of entrainment, transport, accumulation and post-depositional alterations of sedimentary particles, so variations of size distributions of sedimentary particles and granulometric proxies have widely been applied in paleoclimatic reconstructions (Porter and An, 1995; Ding et al., 1999, 2001, 2002; Rousseau et al., 2002;

\footnotetext{
* Corresponding author.

Email address: varga.gyorgy@csfk.mta.hu (G. Varga)
}

Nugteren and Vandenberghe, 2004; Prins et al., 2007; Prins and Vriend, 2007; Vandenberghe, 2013; Liu et al., 2016; Újvári et al., 2016). As a consequence of extremely selective nature of aeolian sedimentation the grain size of windblown deposits is falling into a fairly narrow range (Pye, 1987; Tsoar and Pye, 1987; Shao, 2008). Therefore, information on provenance, various aspects of aeolian sedimentation and depositional environment can be reconstructed only from accurate grain size data via a correct sedimentary and paleoclimatic interpretation.

Nowadays, modern, state-of-the-art measurements of granulometric properties of dust deposits have been easily accessible for researchers. Measurements of particle size can be performed by a variety of instrumental techniques such as sieve and pipette method, laser scattering and image analysis of pictures taken by optical or scanning electron microscopes. Grain size distribution (GSD) data obtained from the most widely used particle sizing technique, the laser light 
scattering measurement provides information on the volumetric amount of particles arranged into ca. 100 size bins ranging from hundreds of nanometres up to several millimetres in size. It is known to be a robust method with much more accurate and reliable information on the major granulometric properties of windblown sediments compared to the sieve and pipette methods (Konert and Vandenberghe, 1997). It is worth noting, however, laser scattering particle size data is indirect information on the sphere equivalent diameter of the particle; the light scattering pattern of the measurements must be transformed by different optical models (Fraunhofer and Mie theories) to attain particle size distribution data.

Shape of generally polymodal GSD curves with a dominant mode in the middle and coarse silt fraction and a secondary one in the clay-, fine silt range is thought to be the product of simultaneously acting sedimentary factors, post-depositional alterations and also the effects of optical models and settings applied during the measurements (Sun et al., 2004; Weltje and Prins, 2007; Özer et al., 2010; Vandenberghe, 2013). These different mechanisms can be decomposed by using different mathematical-statistical methods (e.g. parametric curve-fitting, end-member modelling), however, the approach and scope of these techniques is different, the interpretation of the subpopulations cannot be implicit. Additionally, cluster analysis was chosen to identify different sedimentary units, (sub)populations of the loess-paleosol series.

There are three primary aims of this study: (1) to discuss the differences of frequently applied grain size data interpretation approaches and methods; (2) to ascertain the main reasons of these revealed differences; and (3) to provide a comprehensive overview on the geological importance and genetically meaning of the subtracted sedimentary (sub)populations and clusters.

\section{Location and geological setting}

\subsection{Stratigraphy}

More than half of the area of the Carpathian Basin (Central Europe) is covered by windblown loess and loess-like deposits. The cyclic climatic and other environmental variations of Quaternary glacial and interglacial periods can be reconstructed from the alternating loess and paleosol units of the several tens of metres thick aeolian dust deposits, which are among the most important terrestrial archives of the last 1 million years of Europe. During Pleistocene glacials, the increased dust flux and cold-dry climate provided suitable conditions for formation of the thick pale yellow loess, while soils were formed during the more humid and warm interglacials from the previously deposited windblown loess with some additional admixture of fine-grained background dust.

The studied loess-paleosol section is located at Dunaszekcső on the right bank of River Danube in Southern Hungary $\left(46^{\circ} 05^{\prime} 25^{\prime \prime} \mathrm{N}\right.$, $18^{\circ} 45^{\prime} 45^{\prime \prime} \mathrm{E}, 135 \mathrm{~m}$ a.s.1. - Fig. 1.) and exposes the last glacial-interglacial sedimentary units with a thickness of $14.57 \mathrm{~m}$ (detailed sedimentological description is presented by Újvári et al., 2014). The base of the investigated section is homogeneous calcareous MIS-6 loess, however, neither this unit nor the whole underlying $\sim 55 \mathrm{~m}$ thick Quaternary loess-paleosol sequence are not part of this study. The MIS-5 is represented by a $2.2 \mathrm{~m}$ thick reddish-brown pedocomplex (S1) comprised from two brown soil units intercalated by yellowish-gray loess layer (MIS-5b). The upper (MIS-5a) soil is less well-developed than the thicker MIS-5e unit which one is separated from the underlying loess by carbonate concretion bed with $1-10 \mathrm{~cm}$ in diameter large concretions. The pedocomplex is overlain by the L1 unit consisting of two loess layers (L1L1; L1L2) and one altered, weakly developed soil horizon (L1S1) corresponding to MIS-2 to MIS-4 stages. The L1L2 loess is grayish-yellow to brownish-yellow, relatively porous with a thickness of $1.3 \mathrm{~m}$, while the L1L1 is $6 \mathrm{~m}$ thick, pale yellow, calcareous, sometimes sandy loess, the intercalated MIS-3 pedogene unit is an altered, weakly developed soil horizon $(2.7 \mathrm{~m})$. The Pleistocene sequence is separated from the modern dark brown chernozem soil (S0) soil by a sharp boundary; the upper half of this soil is heavily affected by anthropogenic activity.

After cleaning of the sediment surface 304 samples were collected from a depth of 2-14.57 m; the upper part (2-12.85 m) was sampled at 5-cm intervals, while in case of the lower part (12.85-14.57 m) 2-cm resolution was used due to the proposed lower sedimentation and mass accumulation rates.

\section{Methods \\ 3.1. Grain size measurements}

The particle size distribution of all 304 sedimentary samples was determined after chemical treatment by adapting the procedure used

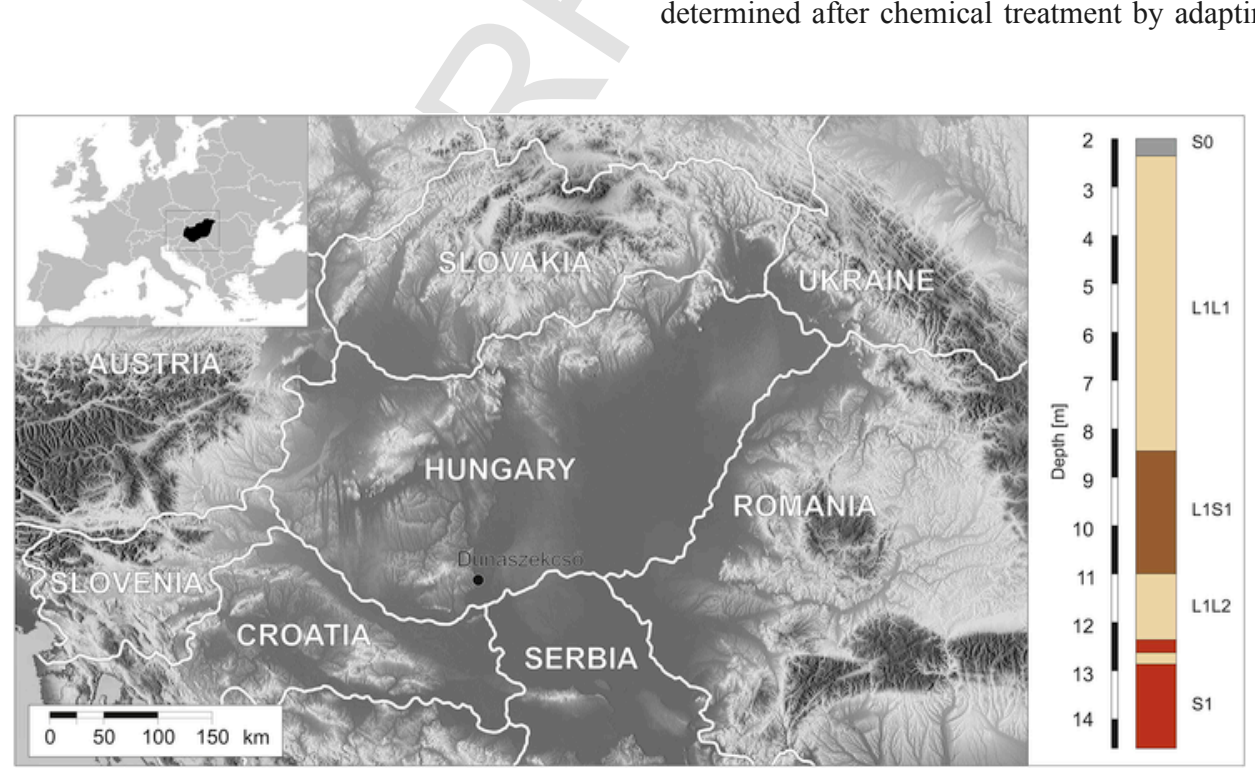

Fig. 1. Location and general stratigraphic units of the investigated loess-paleosol section of Dunaszekcső. 
by Konert and Vandenberghe (1997) to isolate and disperse discrete detrital particles. After treating the samples with $(10 \mathrm{ml}, 30 \%) \mathrm{H}_{2} \mathrm{O}_{2}$ to oxidize the organic material and $(10 \mathrm{ml}, 10 \%) \mathrm{HCl}$ to remove the carbonate, in order to disperse the particles $10 \mathrm{ml}$ of $3.6 \%$ $\mathrm{Na}_{4} \mathrm{P}_{2} \mathrm{O}_{7} \cdot 10 \mathrm{H}_{2} \mathrm{O}$ was added to the samples. The measurements were made on a Malvern Mastersizer 3000 (Hydro LV) laser scattering device.

Particle size data are determined as volume percentage of particles classed into 101 logarithmically distributed (log-spaced) size bins from 0.01 to $3000 \mu \mathrm{m}$. Laser light scattering patterns of two light sources (red $633 \mathrm{~nm}$; blue LED: $470 \mathrm{~nm}$ ) were measured by focal plane detectors, side and backward scattered light detectors. The acquired signal is transformed by the laser device software into particle size distribution data by using Fraunhofer or Mie scattering theory. For the Mie approach, as it is a solution for Maxwell's electromagnetic field equations the knowledge of optical properties (refractive index and absorption coefficient [imaginary part of the complex refractive index]) of sample and dispersant is needed, 1.54 refractive index and 0.1 absorption coefficient (1.54-i0.1) were applied for the samples, while 1.33 refractive index was used for the dispersant water.

Reported refractive indices of loess and soil-forming minerals generally fall within a relatively narrow range, however, the value of absorption coefficient is dependent also on particle shape and surface roughness beside the mineralogical composition. In order to get an overview on particles size distributions and on effects of optical settings, some additional calculations were made with the combination of various refractive indices ( $\mathrm{Ri}: 1.45-1.6)$ and absorption coefficients (Ac: 0.01-1).

\subsection{Statistics}

Beside the widely used plain statistical parameters (mean, median, mode, kurtosis, skewness) and simple size fraction ratio-based indicators (e.g. U-ratio [he ratio of 16-44 $\mu \mathrm{m} / 5.5-16 \mu \mathrm{m}$ fractions by Vandenberghe et al., 1997], Grain Size Index [GSI: the ratio of 20-50 $\mu \mathrm{m} /<20 \mu \mathrm{m}$ fractions by Rousseau et al., 2002]), some more complex descriptors were also calculated from the raw grain size data.

\subsubsection{Parametric curve fitting}

Generally, the GSDs of sedimentary samples after a single transportation episode can be described as unimodal frequency curves. When more than one transportation mode is involved in the sedimentary process, then the particles size frequency curves are showing a bimodal or polymodal shape (Sun et al., 2002, 2004). According to the applied parametric curve fitting technique the bimodal particle size curves can be interpreted as sum of two overlapping Weibull-functions which represent two sediment populations:

$$
\begin{aligned}
W_{1}+W_{2}= & c_{1} \times\left(\frac{\alpha_{1}}{\beta_{1}^{\alpha_{1}}}\right) \times x^{\alpha_{1}-1} \times e^{-\left(\frac{x}{\beta_{1}}\right)^{\alpha_{1}}} \\
& +c_{2} \times\left(\frac{\alpha_{2}}{\beta_{2}^{\alpha_{2}}}\right) \times x^{\alpha_{2}-1} \times e^{-\left(\frac{x}{\beta_{2}}\right)^{\alpha_{2}}},
\end{aligned}
$$

where, shape $(\alpha)$, location $(\beta)$ and weighting (c) parameters of the two Weibull-functions were modified by an iterative numerical method as a least-square problem to assess the appropriate goodness of fit of measured data and calculated size distributions of constructed subpopulations (Varga et al., 2012).

\subsubsection{End-member modelling}

The linear mixing model to unmix sedimentary dynamic populations by end-member modelling was developed by Weltje (1997) and has widely been applied in sedimentary analysis of aeolian dust deposits (Vriend and Prins, 2005; Prins et al., 2007; Prins and Vriend, 2007; Bokhorst et al., 2011; Stuut et al., 2014). The numerical technique is based on the simultaneous analysis of a whole sequence based on the covariance structure of the dataset by using principles of eigenspace analysis and different scaling procedures to describe GSDs as a linear combination of end-members and their weighting scores (Dietze et al., 2012). After the estimation of minimum number of end members required for an appropriate approximation of the measured data, the size distributions and weighting scores for every end-members are determined. For this calculations the EMMAgeo for Matlab (developed by Dietze et al., 2012) was applied.

\subsubsection{Cluster analysis}

Grain size classes were the input variables of cluster analysis. The calculated Euclidean distance between pairs of objects in [304 $\times 101]$ data matrix (, where the 304 rows correspond to samples and 101 columns correspond to grain size bins) were used to create a hierarchical cluster tree, however, calculations with various size bin windows (e.g. clay, fine silt, coarse silt fractions; so less bins, less columns in the data matrix) were also performed to identify main drivers of clustering.

\section{Results}

\subsection{Simple statistics and grain size indicators}

Changes of settings of complex refractive indices applied for the laser scattering measurements have an effect on the GSDs as well on the derived statistical indicators (Fig. 2). The differences of various optical settings are clearly visible in case of finer size fractions, but there are no significant differences in the medium and coarse silt content (therefore it has minor effect on the mode of distribution curves). Optical setting changes are able to create an additional maximum in the submicron fractions, which lead to an increase in the clay-sized fraction.

The separate effects of various refractive index (Ri) and absorption coefficient (Ac) settings were also analysed (Fig. 3). In the case of the $\mathrm{Ri}$ effect analyses, the Ac values were held constant at $0.01,0.1$ and 1 , while Ri values were varied between 1.45 and 1.6. The Ri settings significantly affected the grain size distribution, particularly $\mathrm{Ri}<1.5$; however Ri effect was less pronounced in the case of higher values, which lead to an almost constant clay content. As a consequence, Ri settings have resulted similar patterns in an opposite direction to median grain size value changes primarily determined by modification of clay and fine silt content rather than changes of coarser components.

In order to analyse the effect of Ac settings the Ri value was held constant at 1.54, and the Ac values were varied between 0.01 and 1 (from almost transparent to totally opaque). While the Ri values of most soil-forming minerals can be found in the literature, their Ac values are not available neither cannot be measured precisely in case of relatively small particles (e.g. clay minerals).

Laser scattering measurements show that the majority of mineral particles of the samples fall into silt ranges with minor clay and very fine sand components (Fig. 4.). All of our measured loess grain size distribution curves have fairly similar, uniform shape patterns with definite positive skewness (asymmetry into the direction of coarse fractions), unimodality (or weakly developed bimodality) and lep- 

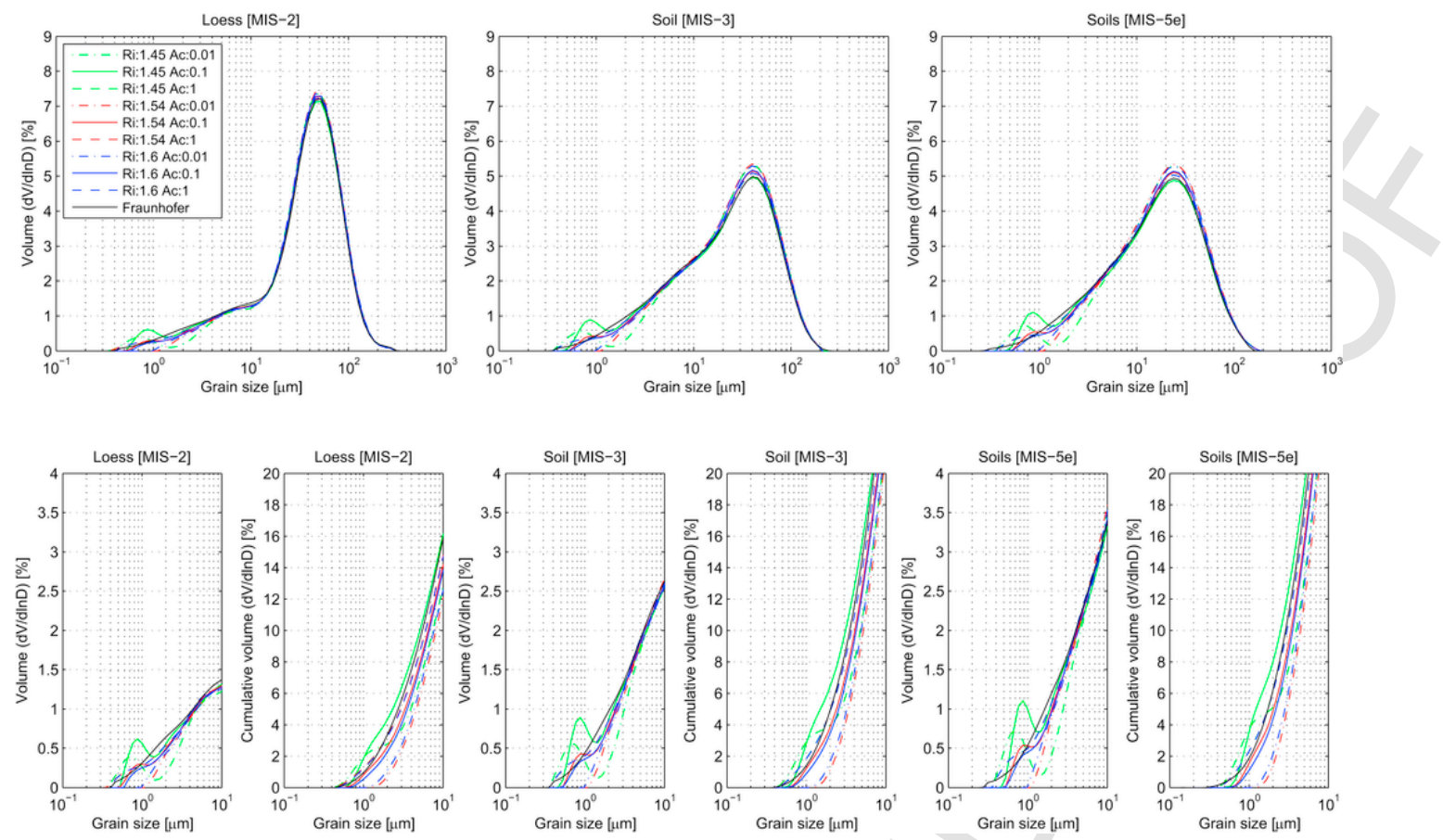

Fig. 2. Grain size distribution curves of different sedimentary units by using different optical setting of the laser scattering device.
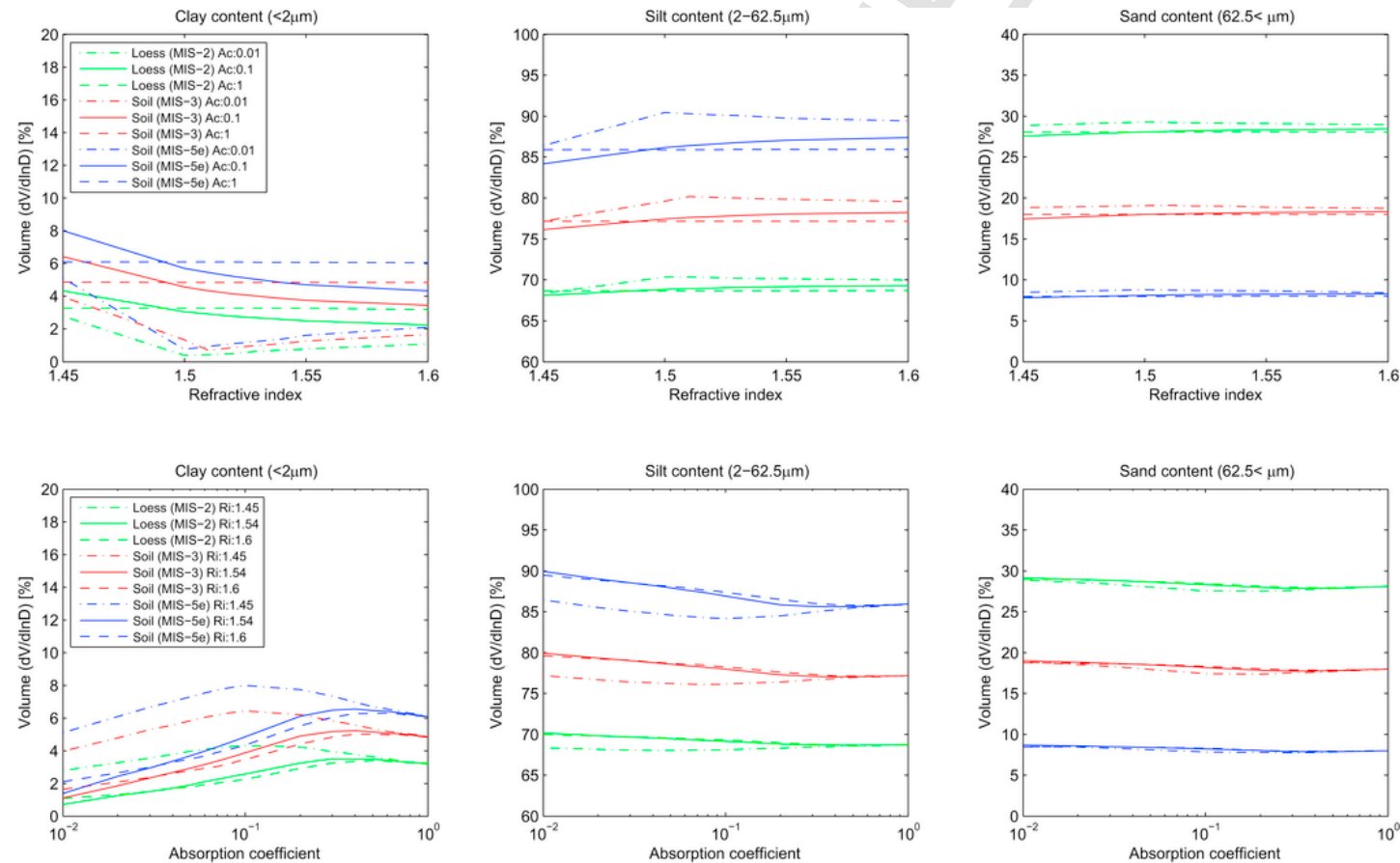

Fig. 3. Separate effects of refractive index and absorption coefficient settings on different grain size fractions of loess and paleosol samples.

tokurtic kurtosis. The pronounced maximum in medium and coarse silt fraction and a tail or shoulder in the clay and fine silt components indicate a primary aeolian depositional environment. Paleosols have more complex granulometric profile with slightly lower mean and modal grain size, higher clay-content, slightly modest kurtosis and a more distinct clay/fine silt shoulder compared to unweathered loess.

Overwhelming volume-based majority of particles fell into the silt-sized $(2-62.5 \mu \mathrm{m})$ fractions with mean values of $75.5-81.4 \mathrm{vol} \%$ for loess and $81-87.8$ vol\% for pedogene units. Loess deposits can be characterized by higher sand (16.6-21.1 vol \%) and lower clay (3-3.4 vol \%) contents compared to the soil horizons (clay: 3.4-5.6 vol\%; sand: $6.6-15.3$ vol \%). The highest clay content was measured in lowermost part of the section, while the sand fraction increases gradually in the upward direction of the section (Table 1.).

Mean and modal grain sizes ( \pm standard deviation of the samples) of the loess units are $36.5 \pm 5.5 \mu \mathrm{m}$ and $45.9 \pm 6.9 \mu \mathrm{m}$, while these 


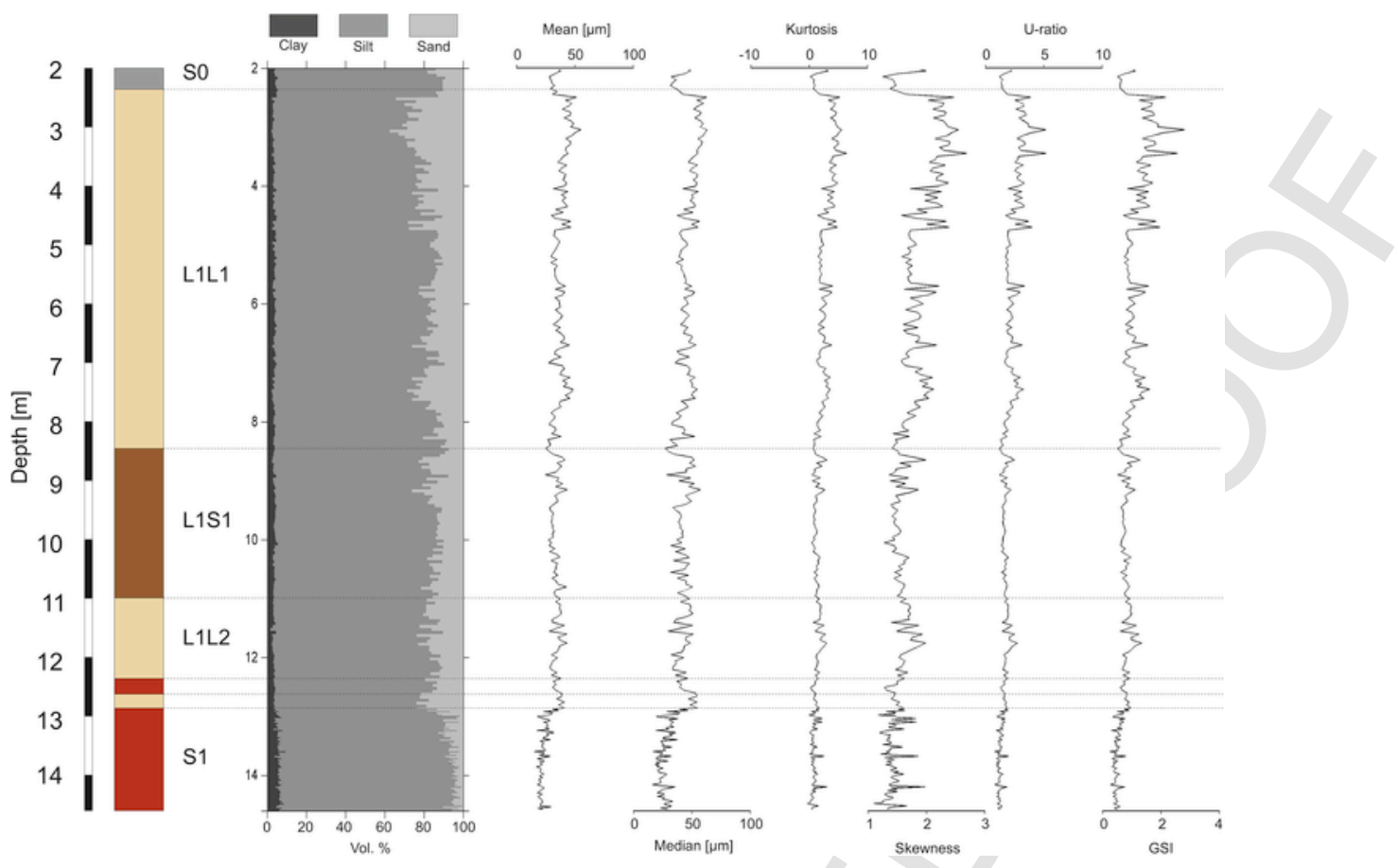

Fig. 4. Variations of grain size fractions, simple statistical descriptors and indices as a function of depths in the Dunaszekcső profile.

Table 1

Results of simple statistical descriptors and indices by stratigraphic units.

\begin{tabular}{|c|c|c|c|c|c|c|c|c|c|c|c|}
\hline Unit & & Age & Clay [vol. \%] & Silt [vol. \%] & Sand [vol. \%] & Mean $[\mu \mathrm{m}]$ & Mode $[\mu \mathrm{m}]$ & Kurtosis & Skewness & U-ratio & Grain Size Index \\
\hline S0 & soil & MIS-1 & 4.19 & 83.39 & 12.42 & 30.70 & 37.60 & 1.05 & 1.52 & 1.60 & 0.71 \\
\hline L1L1 & loess & MIS-2 & 3.34 & 76.96 & 19.70 & 37.14 & 46.82 & 2.73 & 1.93 & 2.48 & 1.18 \\
\hline L1S1 & weakly developed soil & MIS-3 & 3.44 & 81.39 & 15.17 & 31.86 & 41.54 & 1.05 & 1.53 & 1.67 & 0.77 \\
\hline L1L2 & loess & MIS-4 & 3.03 & 80.36 & 16.61 & 33.69 & 41.33 & 1.53 & 1.66 & 1.91 & 0.89 \\
\hline \multirow[t]{3}{*}{ S1 } & soil & MIS-5a & 3.71 & 81.03 & 15.26 & 31.74 & 40.48 & 0.41 & 1.37 & 1.48 & 0.67 \\
\hline & weathered loess & MIS-5b & 3.39 & 75.48 & 21.13 & 36.67 & 50.64 & 0.87 & 1.47 & 1.68 & 0.82 \\
\hline & soil & MIS-5e & 5.60 & 87.79 & 6.62 & 22.14 & 26.81 & 0.63 & 1.42 & 1.30 & 0.50 \\
\hline
\end{tabular}

simple statistical descriptors for the soil deposits are $26.2 \pm 6.2 \mu \mathrm{m}$ and $32.8 \pm 9.5 \mu \mathrm{m}$, respectively. The lowest values were measured in the lowermost part of the profile. The ratios of mean and modal values suggest a stronger skewness for the loess units in the direction of coarser particles, the calculated values for skewness are $1.86 \pm 0.28$ for loess and $1.46 \pm 0.15$ for soil samples. Another shape indicator parameter of GSD curves is the kurtosis, which is $2.44 \pm 1.19$ in case of loess, while significantly lower values were calculated for the pedogene units: $0.79 \pm 0.58$.

Results of U-ratio and GSI calculations based on different size fraction ratios indicated a very similar pattern along the profile with an explicit similarity with other simple statistical indices.

\subsection{Parametric curve fitting}

By fitting the cumulative curve of two 3-parameter Weibull-distributions via an iterative algorithm, excellent goodness-of-fit values $\left(r^{2}>0.995\right)$ were reached between the measured GSDs and calculated cumulative distribution functions. Down-profile variations of the weighting factor and the two shape parameters are presented in Fig. 5 , where $\mathrm{W}_{1}$ is the fine-grained, $\mathrm{W}_{2}$ is the coarse-grained population. As the $\beta$ location parameters (which determine the position of the modes of fitted curves) can easily be converted to modal values, via the following function:

$\mathrm{Md}=0.0081 \times \mathrm{e}^{0.128 \times \beta}$,

based on the log-spaced grain size bin allocation of the laser scattering device.

It is clearly visible that the $\alpha$ and $\beta$ shape parameters of the fine-grained fractions are showing a relatively stable character except for the lowermost part of the section. At the same time, the values of $\mathrm{W}_{2}$ populations are fairly diverse with a general downward decreasing trend in both cases, indicating the presence of more platycurtic $\mathrm{W}_{2}$ GSDs with a progressive fining of modal sizes.

The different stratigraphic units can be described by different typical volumetric proportions of fitted Weibull-distributions. The $\mathrm{W}_{1}$ and $\mathrm{W}_{2}$ volumetric per cents are 10-20 and 80-90 for loess strata, and 20-30 and 70-80 for the pedogene units (Table 2.).

\subsection{End-member modelling}

Goodness-of-fit values $\left(\mathrm{r}^{2}\right)$ of modelled end member combinations versus measured GSDs can be set into the range between 0.15 and 0.95 with an average of 0.6 . Two from the three calculated EMs are the dominant components of the modelling process. Fig. 6 provides 

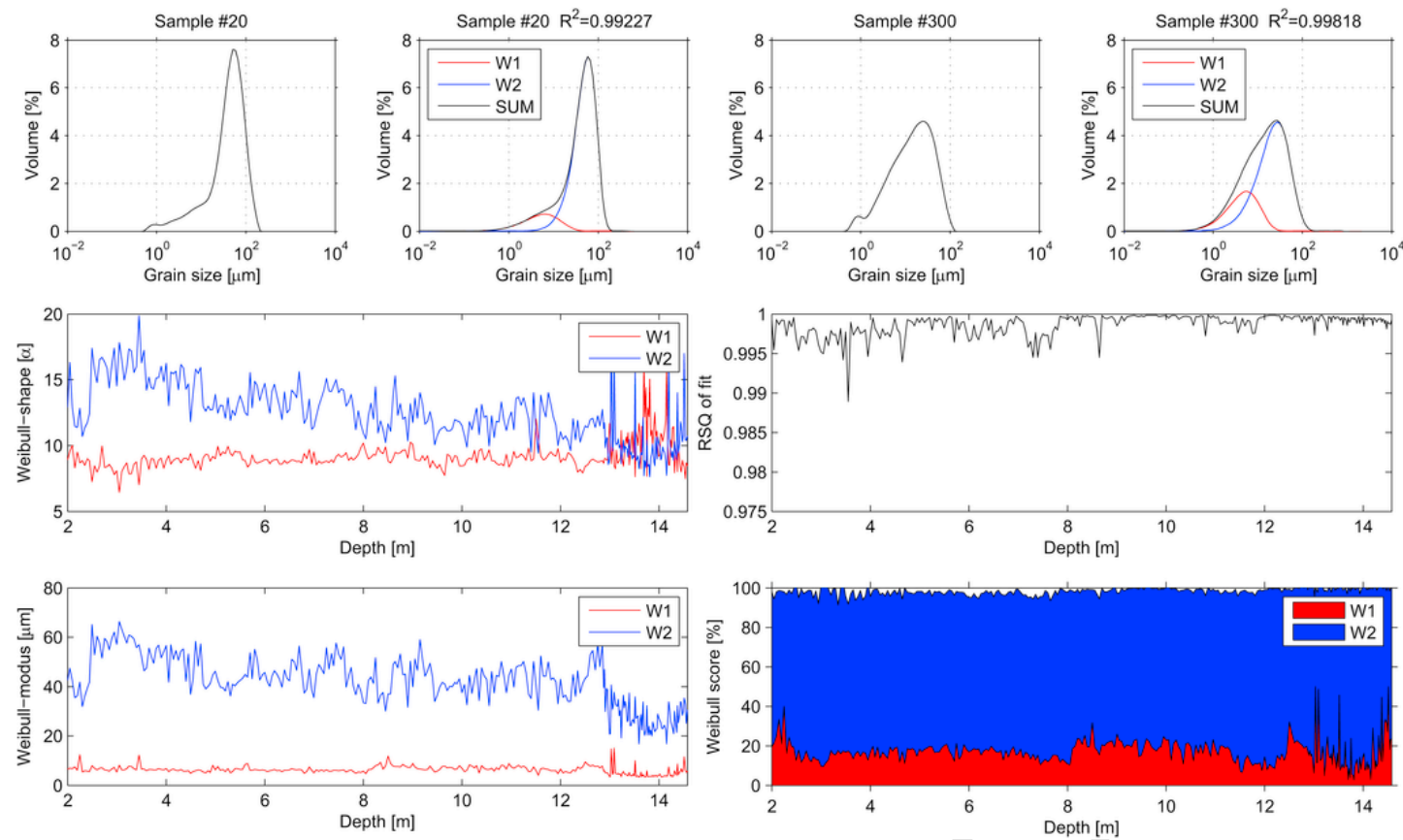

Fig. 5. Results of the parametric curve-fitting by applying two Weibull-distributions: typical examples of fittings; down-profile goodness-of-fit and parameter distribution.

Table 2

Results of subpopulation decomposition via end-member modelling and parametric curve-fitting by stratigraphic units.

\begin{tabular}{|c|c|c|c|c|c|c|c|c|c|c|c|c|}
\hline \multirow[t]{3}{*}{ Unit } & \multirow[t]{3}{*}{ Age } & \multicolumn{4}{|c|}{ End-member modelling } & \multicolumn{7}{|c|}{ Parametric curve-fitting } \\
\hline & & \multirow[t]{2}{*}{ EM1 [vol. \%] } & \multirow[t]{2}{*}{ EM2 [vol. \%] } & \multirow[t]{2}{*}{ EM3 [vol. \%] } & \multirow[t]{2}{*}{$r^{2}$} & \multirow{2}{*}{$\frac{W_{1}}{\alpha_{1}}$} & $\square$ & \multirow{2}{*}{$\mathrm{c}_{1}$ [vol. \%] } & \multicolumn{3}{|l|}{$\mathrm{W}_{2}$} & \multirow[t]{2}{*}{$r^{2}$} \\
\hline & & & & & & & $\beta_{1}$ modus $[\mu \mathrm{m}]$ & & $\alpha_{2}$ & $\beta_{2}$ modus $[\mu \mathrm{m}]$ & $\mathrm{c}_{2}$ [vol. \%] & \\
\hline S0 & MIS-1 & 28.17 & 23.35 & 48.49 & 0.3812 & 9.04 & 6.47 & 24.94 & 12.48 & 36.57 & 72.67 & 0.9984 \\
\hline L1L1 & MIS-2 & 72.33 & 21.85 & 5.82 & 0.6577 & 8.86 & 5.80 & 16.05 & 14.09 & 44.57 & 81.38 & 0.9979 \\
\hline L1S1 & MIS-3 & 52.56 & 42.14 & 5.30 & 0.6477 & 9.02 & 6.66 & 19.94 & 11.85 & 39.48 & 79.10 & 0.9994 \\
\hline L1L2 & MIS-4 & 68.06 & 31.94 & 0.00 & 0.6081 & 9.22 & 5.82 & 13.02 & 11.83 & 39.07 & 85.35 & 0.9991 \\
\hline \multirow[t]{3}{*}{$\mathrm{S} 1$} & MIS-5a & 52.18 & 47.82 & 0.00 & 0.7083 & 8.29 & 7.83 & 25.07 & 11.27 & 40.32 & 73.89 & 0.9995 \\
\hline & MIS-5b & 67.34 & 32.66 & 0.00 & 0.7737 & 8.84 & 7.10 & 20.92 & 11.84 & 48.64 & 79.37 & 0.9996 \\
\hline & MIS-5e & 14.46 & 84.48 & 1.06 & 0.5864 & 10.08 & 4.28 & 15.72 & 10.14 & 25.85 & 83.95 & 0.9992 \\
\hline
\end{tabular}

an overview of the end-member modelling results. EM1 has a pronounced peak around $40 \mu \mathrm{m}$ and a secondary mode at $15 \mu \mathrm{m}$. The more fine grained EM2 GSD is also bimodal (peaks are at $2.5 \mu \mathrm{m}$ and $\sim 15 \mu \mathrm{m}$ ) with an additional submicron local maximum.

Weighting scores of these two EMs are responsible for the $94.5 \mathrm{vol}$ $\%$ of the total modelled volume of the whole profile. Majority of the samples are determined by EM1 (especially from 2.40 to $4.80 \mathrm{~m}$ ), but the dominance of EM2 is also clearly visible at the lowermost part of the section and partly between $7.75 \mathrm{~m}$ and $11.40 \mathrm{~m}$. Contribution of the polymodal EM3 is minor compared to the previous ones, and it is worth noting that highest EM3 contributions overlap the lowest goodness-of-fit values.

\subsection{Cluster analysis}

Three different clusters of measured GSDs were determined by hierarchical cluster analysis, the heights of each two connected objects at the compiled polar dendrogram of the hierarchical, binary cluster tree shows similarity-based tightness of the samples. Cluster- 1 contains the coarsest 61 samples with modal grain sizes around $52-58 \mu \mathrm{m}$, the contribution of clay $(<2 \mu \mathrm{m})$ and fine silt-sized $(2-8 \mu \mathrm{m})$ particles is lower than $12-18$ vol \%. Cluster-2 GSDs $(\mathrm{n}=170)$ slightly lower modal grain size $(40-45 \mu \mathrm{m})$ and somewhat higher (18-25 vol \%) fine-grained content compared to Cluster-1 samples. The 73 Cluster-3 samples have the lowest modal grain sizes (20-24 $\mu \mathrm{m})$ and highest fine particle contributions (30-36 vol \%).

The down-profile distribution of the different clusters is also presented at Fig. 7. The coarsest Cluster-1 samples are located at the uppermost part of the loess profile, the majority of the section is determined by the Cluster- 2 members, while the $\mathrm{S} 1$ paleosol layer is comprised of almost solely from GSDs grouped into Cluster-3.

\section{Discussion}

\subsection{Effects of optical settings on results}

Significant differences between the Mie and Fraunhofer approaches were found for the finest grain size fractions, while only slight discrepancies could be observed in cases of medium to coarse silt fractions. Since the two approaches gave similar results for the most abundant loess fractions, the use of the different approaches has no appreciable effect on the mode of the distributions. Similar findings were published by Schulte and Lehmkuhl (in press). In conclusion, the different applied optical parameter settings had significant 

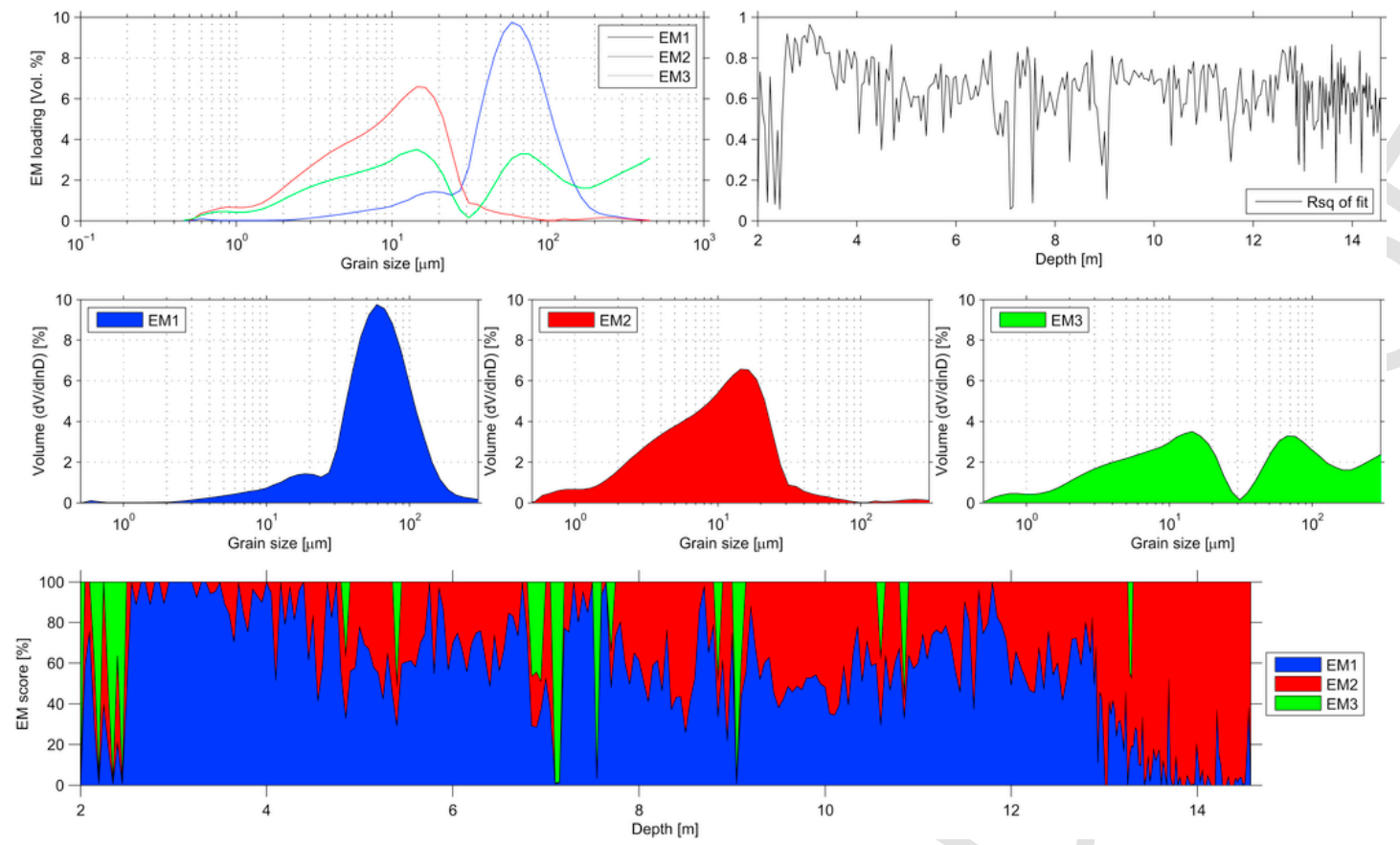

Fig. 6. End-member modelling with three EMs: end-member GSDs; goodness-of-fit and down-profile EM scores.
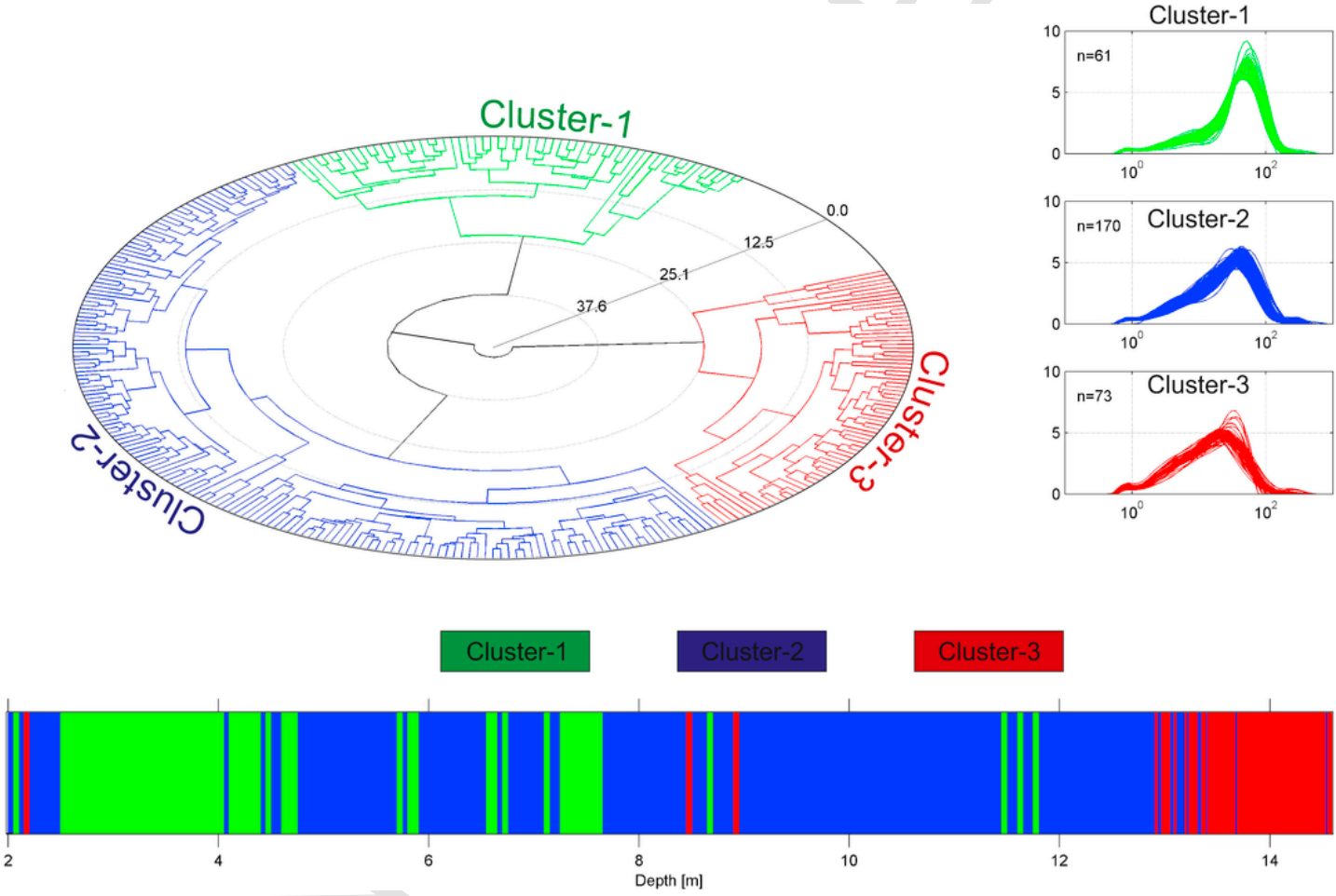

Fig. 7. Results of hierarchic cluster analysis and down-profile distribution of the determined cluster members.

effects on the finer tail of the aeolian grain size distributions, but the derived statistical descriptors and indices are not sensitive to these changes.

Down-profile values of the different indicators are varying in a systematic way as the whole curves drifts with relatively small amplitude as a function of the amount of fine-grained particles. It means if we are using the same optical settings for all samples from the whole investigated profile, the major relative changes of measured data and calculated values will show the general trends. But, absolute values can only be compared if the same optical settings were used.

Effects of optical setting on parametric curve fitting, end-member modelling and cluster analysis were also analysed. As the (sub)population determinations and clustering are based on the whole grain size spectrum the effects of small particles can only be recognized in case 
of $\mathrm{W}_{1}$ fine-grained population of the parametric curve fitting results. In case of the other applied methods, significant differences cannot be detected in the results derived from the data of different optical approaches and settings.

\subsection{Meanings of single statistical descriptors}

Large number of research papers dealing with grain size data apply simple statistical descriptors to draw conclusions on the stratigraphic, sedimentary and evolutionary meaning of granulometric data. The amount and physical properties (e.g. grain size) of mobilized, transported, deposited (and/or redeposited) and postdepositionally altered mineral dust are modified by several simultaneous environmental factors. As it was presented by Újvári et al. (2016), this kind of approach which provide direct linkage among single statistical descriptors (mean, mode or median) and wind speed, strength (Liu et al., 1985; An et al., 1991; Derbyshire et al., 1995), distance from source area (Ding et al., 1999, 2001, 2002, 2005) or aridity/extent of source areas (Sun et al., 2010, 2012) is rather oversimplified as the grain size of sedimentary samples from aeolian dust deposits is influenced by an integrated effects of several concurrent processes (Vandenberghe, 2013). Furthermore, the representativeness of such simple indices derived from complex grain size distribution curves is also a debatable issue.

Beside the complex environmental elements of mobilization, transportation, the sediment availability is also a further control on grain size (Stevens et al., 2011). On the other hand, different depositional modes can also play a role in the modification of the grain size. During dry deposition events, grain size of the deposited dust material is governed also by the level of atmospheric turbulence, particle characteristics and the nature of depositional surface. Previous studies have confirmed that both gravitational settling and turbulent nature of airflow have an effect on particle size (Bagnold, 1941). In case of larger than $50 \mu \mathrm{m}$ grains, deposition is primarily governed by gravity, while removal of smaller fractions is strongly affected by turbulent mixing.

Dust removal by wet deposition can be occurring as in-cloud (rainout) and below-cloud (washout) scavenging. As predominantly submicron particles are taking a part in cloud formation, rainout processes have an effect only on this fraction. However, washout of particles larger than $5 \mu \mathrm{m}$ is the most effective, wet deposition of clay and very fine silt particles is less efficient similarly.

U-ratio values are defined as the ratio of the coarse silt and fine to middle silt fractions. Particles smaller than $5.5 \mu \mathrm{m}$, as these are altered by secondary post-depositional pedogenesis, are eliminated from the calculations as well as $44<\mu \mathrm{m}$ fractions which were likely transported by saltation. Silt fraction ratios in this way are interpreted as proxies of aeolian environment dynamics; high U-ratios indicate strong winds of glacials, while low values are the results of weak winds (Vandenberghe et al., 1985, 1997). The main idea behind GSI is very similar, and this is well reflected by the analogous results consistent with U-ratio.

The simultaneous changes of all of these above listed simple statistical descriptors and indices of grain size variations in the down-profile of Dunaszekcső section do not provide different information on the climatic and other environmental conditions, and as was ascertained by Újvári, G. et al. (2016), 'we do not see clear advantages of using one over the other'. All proxies are the results of an integrated action of several environmental factors.

\section{3. (Sub)population interpretation}

GSDs of aeolian dust deposits are much more complex than simple unimodal statistical distributions describable by single mathematical expressions. The typically bimodal character of GSDs are representing different sedimentary (sub)populations, which can be separated (unmixed) by different mathematical methods. We believe that the differences among the applied two methods of parametric curve fitting and end-member modelling arise from their different approach and scope. Whereas end-member modelling is based on the simultaneous unmixing of the whole data-series based on the covariance structure, the input of the parametric curve fitting is only one GSD. The resulting (and generally) three end-members of loess-paleosol samples can be regarded as representation of the average dust GSD of three temporal aeolian sediment clusters of seasonal or other short-term intervals (Prins and Vriend, 2007; Prins et al., 2007). In case of loess deposits, the subpopulations of parametric curve fitting are proposed to illustrate the background and the local-derived dust components for each sample, which later statement is also confirmed by recent observations of modern dust storms and dust depositional events (McTainsh et al., 1997; Sun et al., 2004; Varga et al., 2016).

Parameters of the fitted Weibull-distributions have got a clear and direct curve-shape specifying meaning; the single values can be used for the deconvoluted populations similarly to single statistical indices. The $\alpha$ parameter defines the shape of the fitted Weibull-distribution, the lower the $\alpha$ values are the flatter the curves are. The $\beta$ parameters fix the position of the distribution on the $\mathrm{x}$-axis, so the modal value of the simulated curve. While values of ' $c$ ' weighting factors are responsible for scaling the curves to sum the 100 volumetric per cent, and so these parameters determine the amount of mathematically differentiated sedimentary populations. The $\alpha$ shape-parameter determines the width, so the size-range of the population, and can be regarded as an indicator of sorting. $\beta$-values of fitted curves represent the size-related factors, highest volumetric amount of particles fall in the $\beta$ th size bin, indicating the strength of dust transporting wind and/or distance of source area.

The connection among grain size and Weibull-parameters are presented at Fig. 8. A stronger relationship was identified among the parameters $\left(\alpha_{2}\right.$ and $\left.\beta_{2}\right)$ of the coarse grained populations $\left(\mathrm{W}_{2}\right)$, compared to the fine-grained $\mathrm{W}_{1}$ populations, indicating an expected stable behaviour of far-travelled background dust material and a more variable coarse-grained population, sensitive to local changes of the atmospheric dynamics of the Carpathian Basin.

The coarse silt-sized EM1 fraction of end-member modelling is typical for loess deposits indicating stronger winds and/or closer source areas. Very similar members of modelling results were reported by IJmker et al. (2012) and Nottebaum et al. (2016) for the coarsest population of other aeolian dust deposits deflated from local sandy dune material. While EM1 from the Chinese Loess Plateau (Vriend and Prins, 2005; Vandenberghe et al., 2006; Vriend et al., 2011), from Tajikistan (Vandenberghe et al., 2006) and from Central Europe (Bokhorst et al., 2011) have slightly different GSDs, but their interpretation is still similar. However, as it was reported by Lehmkuhl and Haselein (2000) strong winds have transport capacity to take up medium sand-sized particles and according to De Ploey (1977) the transportation of these large grains can take place not only as saltation but even in low suspension clouds. These findings also indicate that modal grain size of EM1 is determined not only by transport mechanisms (wind speed and strength), which are often considered as the ruling factors, but the granulometric properties of 

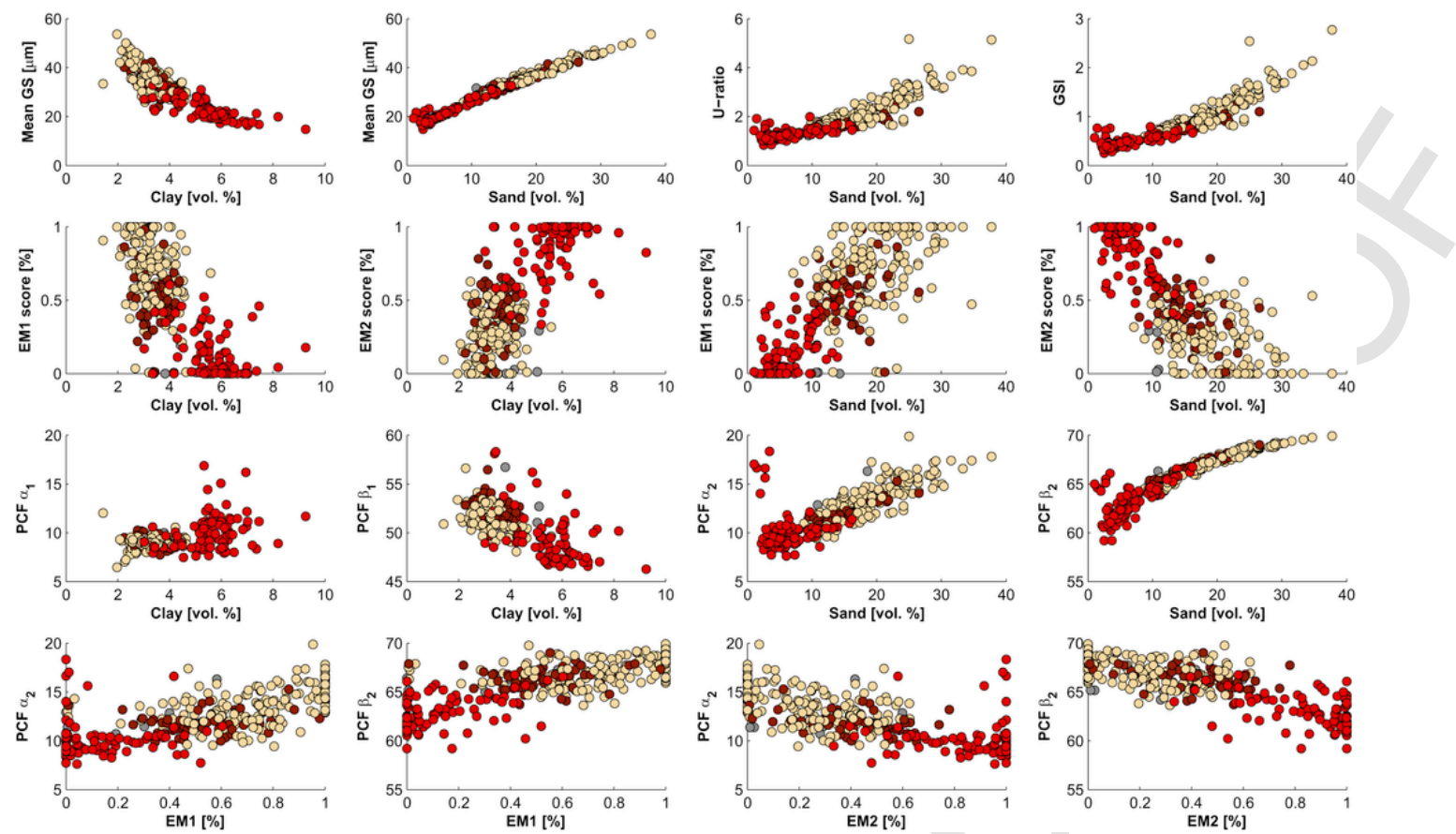

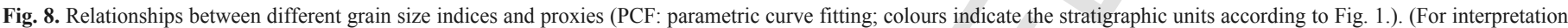
of the references to colour in this figure legend, the reader is referred to the web version of this article.)

the source material and distance of the source area are also important drivers of grain size.

The EM2 is represented by a more complex GSD, the middle silt-sized primary peak and a definite secondary maximum denote weaker wind dynamic patterns and also a higher relative contribution of background dust deposition compared to EM1 populations. Genetically interpretation of EM3 is rather problematic, this group can be explained as a noise-filter in the results when combinations of the two previous end-members are not able to return the measured GSD with an appropriate goodness-of-fit.

As it was already mentioned during the explanation of EM2, these end-members can be the interpreted as the results of more competing process-related factors. End-members represent the average dust GSD of two or three temporal aeolian sediment clusters of seasonal or other short-term intervals.

Result of hierarchic cluster analysis is very similar to end-member scores. The pure loess (Cluster 1, similar to EM1) and pure soil (Cluster 2, equivalent to EM2) groups are completed with a transitional cluster characterized by both of the specifics of other two clusters (represented in the end-member modelling by relatively high values of both end-members).

It is also worth to mention, that statements made on atmospheric dynamics based on loess-paleosol sequences can only be acceptable in case of loess deposits, but paleosol formation is a different topic. According to the classical assumptions for the Carpathian Basin, the glacial loess deposits were formed from the accumulated dust material, while the paleosols were developed from the underlying loess deposits by weak weathering processes. So, grain size of paleosols is determined by the grain size of previously deposited loess and by the effects of pedogenesis (Vandenberghe et al., 2014). Interglacial dust addition to loess-paleosol sequences and interglacial (and Holocene) loess formation have been reported from several other regions (e.g. Chinese Loess Plateau - Vandenberghe et al., 1997; Prins et al., 2007; Vriend et al., 2011; USA, Alaska - Muhs et al., 2004, 2016; USA, Washington State - Busacca, 1989; Israel - Crouvi et al.,
2009), but general characteristics of aeolian dust deposition environment and loess formation of these areas is fairly different from the Central European dust accumulation mechanisms. At regions where accretionary soil formation is the dominant, the application of granulometric proxies derived of paleosols can be able to reflect the various atmospheric dynamics of the interglacials.

\section{Conclusions}

Major characteristics of the granulometric properties of aeolian dust deposits are represented reasonably well by all applied techniques. General upward coarsening of the grain size values of the section is clearly indicated by all of the investigated granulometric descriptors, indices and proxies. However, results of single statistical indices provide very similar section-down curves without clear environmental signals; indicating only some changes in main granulometry. Not to mention the problems of simple statistical indices which are not likely to be representative for polymodal size distribution curves.

Deeper sedimentary and genetically meanings can be deciphered by the application of more complex mathematical algorithms. Parametric curve-fitting is based on the one-by-one break-up of polymodal grain size distribution curves into aggregates of unimodal statistical probability distribution functions (in this case Weibull-functions were applied). End-member modelling provide fix sedimentary populations and the measured grain size distribution curves of the samples are composed from these 'end-members' by weighting them with an appropriate score. As the input for this later method is the whole data-series and end-members are held fix and constant, the goodness-of-fit values are not as high as parametric curve-fitting scores.

End-members of loess-paleosol samples are regarded as representation of the average dust grain size distribution of various temporal sediment clusters of seasonal or other short-term intervals, while (sub)populations by parametric curve-fitting are proposed to illustrate 
process-related elements of background and dust storm depositional components for each sample. The end-members were calculated from the whole grain size database of the investigated section, while the input for the parametric curve fitting is only one sample. The end-members are polymodal, the simple probability density functions of parametric curve fitting are logically unimodal. The polymodal end-members cannot be regarded as the representation of a single dust transportation and/or sedimentation process; these are illustrated by the Weibull functions. The end-members can only be considered as the result of more simultaneous sedimentation mechanisms, which are dominant in a specific period of a year (e.g. seasonal dust signal: spring dust storms connected to the arrival of cold fronts). Results of cluster analysis represent similar grouping conditions as end-member modelling with a reduced sedimentary and genetically meaning.

To develop a full granulometric picture joint application of parametric curve-fitting and end-member modelling is suggested. Parametric deconvolution of the fix and stable end-members the process related seasonal aeolian sedimentary dynamics could be recognized. Another source of uncertainty, the optical setting dependence of laser scattering grain size measurements deserves also a more accurate analytical attitude and correct description in methodological sections of the research papers.

\section{Acknowledgement}

Support of the National Research, Development and Innovation Office (NKFI) under contract NKFI K120620 (for G. Varga) is gratefully acknowledged. It was additionally supported (for G. Varga) by the Bolyai János Research Scholarship of the Hungarian Academy of Sciences.

\section{References}

An, Z.S., Kukla, G., Porter, S.C., Xiao, J.L., 1991. Late quaternary dust flow on the Chinese loess plateau. Catena 18, 125-132.

Bagnold, R.A., 1941. The Physics of Blown Sand and Desert Dunes. Chapman and Hall, New York, 265.

Basarin, B., Buggle, B., Hambach, U., Marković, S.B., O'Hara Dhand, K., Kovačević, A., Stevens, T., Guo, Z., Lukić, T., 2014. Time-scale and astronomical forcing of Serbian loess-paleosol sequences. Global Planet. Change 122, 89-106.

Bokhorst, M.P., Vandenberghe, J., Sümegi, P., Łanczont, M., Gerasimenko, N.P. Matviishina, Z.N., Marković, S.B., Frechen, M., 2011. Atmospheric circulation patterns in central and eastern Europe during the Weichselian Pleniglacial inferred from loess grain-size records. Quatern. Int. 234, 62-74.

Buggle, B., Hambach, U., Müller, K., Zöller, L., Marković, S.B., Glaser, B., 2014. Iron mineralogical proxies and Quaternary climate change in SE-European loess-paleosol sequences. Catena 117, 4-22.

Busacca, A.J., 1989. Long Quaternary record in Eastern Washington, U.S.A., interpreted from multiple buried paleosols in loess. Geoderma 45, 105-122.

Crouvi, O., Amit, R., Porat, N., Gillespie, A.R., McDonald, E.V., Enzel, Y., 2009. Significance of promary hilltop loess in reconstructing dust chronology, accretion rates and sources: an example from the Negev Desert, Israel. J. Geophys. Res. 114, F02017https://doi.org/10.1029/2008JF001083.

De Ploey, J., 1977. Some experimental data on slopewash and wind action with reference to Quaternary morphogenesis in Belgium. Earth Surf. Proc. 2, 101-115.

Derbyshire, E., Kemp, R., Meng, X., 1995. Variations in loess and palaeosol properties as indicators of palaeoclimatic gradients across the Loess Plateau of North China. Quat. Sci. Rev. 14, 681-697.

Dietze, E., Hartmann, K., Diekmann, B., IJmker, J., Lehmkuhl, F., Opitz, S., Stauch, G., Wünnemann, B., Borchers, A., 2012. An end-member algorithm for deciphering modern detrital processes from lake sediments of Lake Donggi Cona, NE Tibetan Plateau. China. Sediment. Geol. 243-244, 169-180.

Ding, Z.L., Ren, J.Z., Yang, S.L., Liu, T.S., 1999. Climate instability during the penultimate glaciation: evidence from two high-resolution loess records, China. J. Geophys. Res. 104, 20123-20132.

Ding, Z.L., Yu, Z.W., Yang, S.L., Sun, J.M., Xiong, S.F., Liu, T.S., 2001. Coeval changes in grain size and sedimentation rate of eolian loess, the Chinese Loess Plateau. Geophys. Res. Lett. 28, 2097-2100.

Ding, Z.L., Derbyshire, E., Yang, S.L., Yu, Z.W., Xiong, S.F., Liu, T.S., 2002. Stacked 2.6-Ma grain size record from the Chinese loess based on five sections and corre- lation with the deep-sea $\delta^{18} \mathrm{O}$ record. Paleoceanography 17, https://doi.org/10. 1029/2001PA000725.

Ding, Z.L., Derbyshire, E., Yang, S.L., Sun, J.M., Liu, T.S., 2005. Stepwise expansion of desert environment across northern China in the past $3.5 \mathrm{Ma}$ and implications for monsoon evolution. Earth Planet. Sci. Lett. 237, 45-55.

IJmker, J., Stauch, G., Dietze, E., Hartmann, K., Diekmann, B., Lockot, G., Opitz, S., Wünnemann, B., Lehmkuhl, F., 2012. Characterisation of transport processes and sedimentary deposits by statistical end-member mixing analysis of terrestrial sediments in the Donggi Cona lake catchment, NE Tibetan Plateau. Sediment. Geol. $281,166-179$

Konert, M., Vandenberghe, J., 1997. Comparison of laser grain-size analysis with pipette and sieve analysis: a solution for the underestimation of the clay fraction. Sedimentology 44, 523-535.

Lehmkuhl, F., Haselein, F., 2000. Quaternary paleoenvironmental change on the tibetan plateau and adjacent areas (western China and western Mongolia). Quatern. Int. 68-71, 117-132.

Liu, T.S., et al., 1985. Loess and the Environment. China Ocean Press, Beijing, 251.

Liu, X., Vandenberghe, J., An, Z., Li, Y., Jin, Z., Dong, J., Sun, Y., 2016. Grain size of Lake Qinghai sediments: implications for riverine input and Holocene monsoon variability. Palaeogeogr. Palaeocl 449, 41-51.

Marković, S.B., Hambach, U., Stevens, T., Kukla, G.J., Heller, F., McCoy, W.D., Oches, E.A., Buggle, B., Zöller, L., 2011. The last million years recorded the Stari Slankamen (Northern Serbia) loess-palaeosol sequence: revised chronostratigraphy and long-term environmental trends. Quat. Sci. Rev. 30, 1142-1154.

Marković, S.B., Stevens, T., Kukla, G.J., Hambach, U., Fitzsimmons, K.E., Gibbard, P., Buggle, B., Zech, M., Guo, Z., Hao, Q., Wu, H., O'Hara Dhand, K., Smalley, I.J., Újvári, G., Sümegi, P., Timar-Gabor, A., Veres, D., Sirocko, F., Vasiljević, D.A., Jary, Z., Svensson, A., Jović, V., Lehmkuhl, F., Kovács, J., Svirčev, Z., 2015. Danube loess stratigraphy - towards a pan-European loess stratigraphic model. Earth-Sci. Rev. 148, 228-258.

McTainsh, G.H., Nickling, W.G., Lynch, A.W., 1997. Dust deposition and particle size in Mali, West Africa. Catena 29, 307-322.

Muhs, D.R., McGeehin, J.P., Beann, J., Fisher, E., 2004. Holocene loess deposition and soil formation as competing processes, Matanuska Valley, southern Alaska. Quat. Res. 61, 265-276.

Muhs, D.R., Budahn, J.R., Skipp, G.L., McGeehin, J.P., 2016. Geochemical evidence for seasonal controls on the transportation of Holocene loess, Matanuska Valley, southern Alaska, USA. Aeol. Res. 21, 61-73.

Nottebaum, V., Stauch, G., Hartmann, K., Zhang, J., Lehmkul, F., 2016. Unmixed loess grain size populations along the northern Qilian Shan (China): relationships between geomorphologic, sedimentologic and climatic controls. Quatern. Int. 372, 151-166.

Nugteren, G., Vandenberghe, J., 2004. Spatial climatic variability on the Central Loess Plateau (China) as recorded by grain size for the last 250 kyr. Glob. Planet. Change 41, 185-206.

Özer, M., Orhan, M., Isik, N.S., 2010. Effect of particles optical properties on size distribution of soils obtained by laser diffraction. Environ. Eng. Geosci. 16, 163-173.

Pécsi, M., 1990. Loess is not just the accumulation of dust. Quatern. Int. 7-8, 1-21.

Porter, S.C., An, Z.S., 1995. Correlation between climate events in the North Atlantic and China during the last glaciation. Nature 375, 305-308.

Prins, M.A., Vriend, M., 2007. Glacial and interglacial eolian dust dispersal patterns across the Chinese Loess Plateau inferred from decomposed loess grain-size records. Geochem. Geophys. Geosystems 8, Q07Q05https://doi.org/10.1029/ 2006GC001563.

Prins, M.A., Vriend, M., Nugteren, G., Vandenberghe, J., Lu, H., Zheng, H., Weltje, G.J., 2007. Late Quaternary aeolian dust input variability on the Chinese Loess Plateau: inferences from unmixing of loess grain-size records. Quat. Sci. Rev. 26 230-242.

Pye, K., 1987. Aeolian Dust and Dust Deposits. Academic Press, London, 334.

Pye, K., 1995. The nature, origin and accumulation of loess. Quat. Sci. Rev. 14, $653-667$.

Rousseau, D.-D., Antoine, P., Hatté, C., Lang, A., Zöller, L., Fontugne, M., Ben Othman, D., Luck, J.-M., Moine, O., Labonne, M., Bentaleb, I., Jolly, D., 2002. Abrupt millennial climatic changes from Nussloch (Germany) Upper Weichselian eolian records during the last glaciation. Quat. Sci. Rev. 21, 1577-1582.

Schulte, P., Lehmkuhl, F., 2017. The difference of two laser diffraction patterns as an indicator for post-depositional grain size reduction in loess-paleosol sequences. Palaeogeogr. Palaeocl. https://doi.org/10.1016/j.palaeo.2017.02.022, (in press).

Smalley, I.J., Leach, J.A., 1978. The origin and distribution of the loess in the Danube basin and associated regions of East-Central Europe - a review. Sediment. Geol. $21,1-26$.

Stuut, J.-B.W., Temmesfeld, F., De Deckker, P., 2014. A 550 ka record of aeolian activity near North West Cape, Australia: inferences from grain-size distributions and bulk chemistry of SE Indian Ocean deep-sea sediments. Quat. Sci. Rev. 83, 83-94.

Sun, D., Bloemendal, J., Rea, D.K., Vandenberghe, J., Jiang, F., An, Z., Su, R., 2002. Grain-size distribution function of polymodal sediments in hydraulic and aeolian 
environments, and numerical partitioning of the sedimentary components. Sediment. Geol. 152, 263-277.

Sun, D., Bloemendal, J., Rea, D.K., An, Z., Vandenberghe, J., Lu, H., Su, R., Liu, T.S., 2004. Bimodal grain-size distribution of Chinese loess, and its paleoclimatic implications. Catena 55, 325-340.

Sun, Y.B., An, Z.S., Clemens, S.C., Bloemendal, J., Vandenberghe, J., 2010. Seven million years of wind and precipitation variability on the Chinese Loess Plateau. Earth Planet. Sci. Lett. 297, 525-535.

Sun, Y.B., Clemens, S.C., Morrill, C., Lin, X., Wang, X., An, Z.S., 2012. Influence of Atlantic meridional overturning circulation on the East Asian winter monsoon. Nat. Geosci. 5, 46-49.

Tsoar, H., Pye, K., 1987. Dust transport and the question of desert loess formation. Sedimentology 34, 134-153.

Újvári, G., Varga, A., Raucsik, B., Kovács, J., 2014. The Paks loess-paleosol sequence: a record of chemical weathering and provenance for the last $800 \mathrm{ka}$ in the mid-Carpathian Basin. Quatern. Int. 319, 22-37.

Újvári, G., Kok, J.F., Varga, G., Kovács, J., 2016. The physics of wind-blown loess: implications for grain size proxy interpretations in Quaternary paleoclimate studies. Earth-Sci. Rev. 154, 247-278.

Vandenberghe, J., Mücher, H.J., Roebroeks, W., Gemke, D., 1985. Lithostratigraphy and palaeoenvironment of the pleistocene deposits at maastricht-belvédère, southern limburg, The Netherlands. Meded. Rijks Geol. Dienst 39, 7-18.

Vandenberghe, J., An, Z.S., Nugteren, G., Lu, H., van Huissteden, J., 1997. New absolute time scale for the Quaternary climate in the Chinese loess region by grain-size analysis. Geology 25, 35-38.
Vandenberghe, J., Renssen, H., van Huissteden, K., Nugteren, G., Konert, M., Lu, H., Dodonov, A., Buylaert, J.-P., 2006. Penetration of atlantic westerly winds into central and east asia. Quat. Sci. Rev. 25, 2380-2389.

Vandenberghe, J., 2013. Grain size of fine-grained windblown sediment: a powerful proxy for process identification. Earth-Sci. Rev. 121, 18-30.

Vandenberghe, J., Markovič, S.B., Jovanovič, M., Hambach, U., 2014. Site-specific variability of loess and palaeosols (Ruma, Vojvodina, northern Serbia). Quatern. Int. 334-335, 86-93.

Varga, Gy, Kovács, J., Újvári, G., 2012. Late Pleistocene variations of the background aeolian dust concentration in the Carpathian Basin: an estimate using decomposition of grain-size distribution curves of loess deposits. Neth. J. Geosci. 91, $159-171$.

Varga, G., Cserháti, Cs, Kovács, J., Szalai, Z., 2016. Saharan dust deposition in the Carpathian Basin and its possible effects on interglacial soil formation. Aeol. Res. $22,1-12$.

Vriend, M., Prins, M.A., 2005. Calibration of modelled mixing patterns in loess grain-size distributions: an example from the north-eastern margin of the Tibetan Plateau, China. Sedimentology 52 (1361), 1374.

Vriend, M., Prins, M.A., Buylaert, J.-P., Vandenberghe, J., Lu, H., 2011. Contrasting dust supply patterns across the north-western Chinese Loess Plateau during the last glacial-interglacial cycle. Quatern. Int. 240, 167-180.

Weltje, G.J., 1997. End-member modeling of compositional data: numerical-statistical algorithms for solving the explicit mixing problem. J. Math. Geol. 29, 503-549.

Weltje, G.J., Prins, M.A., 2007. Genetically meaningful decomposition of grain-size distributions. Sediment. Geol. 202, 409-424. 